\title{
Meteorite Impact Origin of Yellowstone Hotspot
}

\author{
Hermann G. W. Burchard \\ Department of Mathematics, Oklahoma State University, Stillwater, USA \\ Email: skeptiker@icloud.com
}

How to cite this paper: Burchard, H. G. W. (2016). Meteorite Impact Origin of Yellowstone Hotspot. Open Journal of Philosophy, 6, 412-419.

http://dx.doi.org/10.4236/ojpp.2016.64038

Received: October 14, 2016

Accepted: October 30, 2016

Published: November 2, 2016

Copyright $\odot 2016$ by author and Scientific Research Publishing Inc. This work is licensed under the Creative Commons Attribution International License (CC BY 4.0).

http://creativecommons.org/licenses/by/4.0/

\begin{abstract}
Origin of the Yellowstone hotspot \& Columbia River Basalts has remained uncertain until now. Here, we present evidence of meteorite impact origin. The hotspot is shallow, only $200 \mathrm{~km}$ deep, invalidating a theory of mantle plume origin. The hotspot track runs from the Yellowstone National Park in NW Wyoming to the volcanic Modoc Plateau in NE California. We present evidence of apparent remnants of an impact crater existing in the Modoc, a large multi-ring structure at least $160 \mathrm{~km}$ diameter. Much of the complex crater has become obliterated by later Cascadia and Sierra orogenies. The crater has a tall 4,100 foot central uplift cone, locally known as Chalk Mountain, consisting of diatomaceous earth, presumably the rebound cone of a meteorite impact. This falsifies a theoretical prohibition of cosmic impact volcanism. Based on recent insights into explosive volcanism a plausible mechanism is proposed for how meteorite impacts can lead to resurgent calderas of the Yellowstone type, \& of apparent LIP origin from thin crust ET impacts, invalidating theoretical constructs of mantle plumes. We mention chaotic terrains, including plutons, arising antipodal to impacts.
\end{abstract}

\section{Keywords}

Yellowstone Hotspot, Meteorite Impact, Mantle Plume, Impact Volcanism, Explosive Volcanism, Mantle Chemistry, Dissolved Volatiles, Diffusive Replenishment, Multi-Ring Impact Structure, Central Uplift, Diatomaceous Earth, Thin-Crust Impact

\section{Yellow Stone Thermal Anomaly, Onset 16.6 Ma NE California}

The Yellowstone thermal anomaly has produced magmatic outflows for about $17 \mathrm{Ma}$, starting from the Modoc Plateau in NE California. Various theories regarding the origin of the Yellowstone "hotspot" (YS) have been proposed, e.g., the mantle plume theory of Canadian geologist J. Tuzo Wilson (Wilson, 1963) but usually credited to Princeton University geologist W. Jason Morgan (Morgan, 1971), and the competitive 
plate tectonic theory of Donald Anderson (Anderson \& Natland, 2005). All of these can now be refuted. We propose to prove conclusively the origin of YS by meteorite (ET) impact on the Modoc plateau at about 16.6 Ma. A plausible mechanism is presented of how an ET impact can produce a hotspot type thermal anomaly. A large igneous province (LIP) normally will be left behind as it did in the case of YS, the widely familiar Columbia River Basalt Province (CRBP), in the US Pacific NW of N California, Oregon and Washington.

LIPs are found around the globe, and apparently the origins of many or even most of these are oceanic, although quite a few occur at margins of continents or even are centrally located at least at present.

Eruptions continue with the progress of time forming resurgent calderas which may result in a hotspot track. Reproduced below as Figure 1 is an instructive geographical diagram (Foulger, 2006, Figure 2 with permission) of calderas in the NW United States along the track of the YS hotspot from the Modoc to NW Wyoming.

The YS thermal anomaly is restricted to the upper mantle, reaching down to a depth of only about $200 \mathrm{~km}$ (Christiansen, Foulger, \& Evans, 2002). Among several more recent papers coming to the same conclusion, cf. the article by Fouch (Fouch, 2012). Being limited in extent to the upper mantle, there can be no thought of it coming into existence by upwelling from the core-mantle boundary, the so-called D" layer.

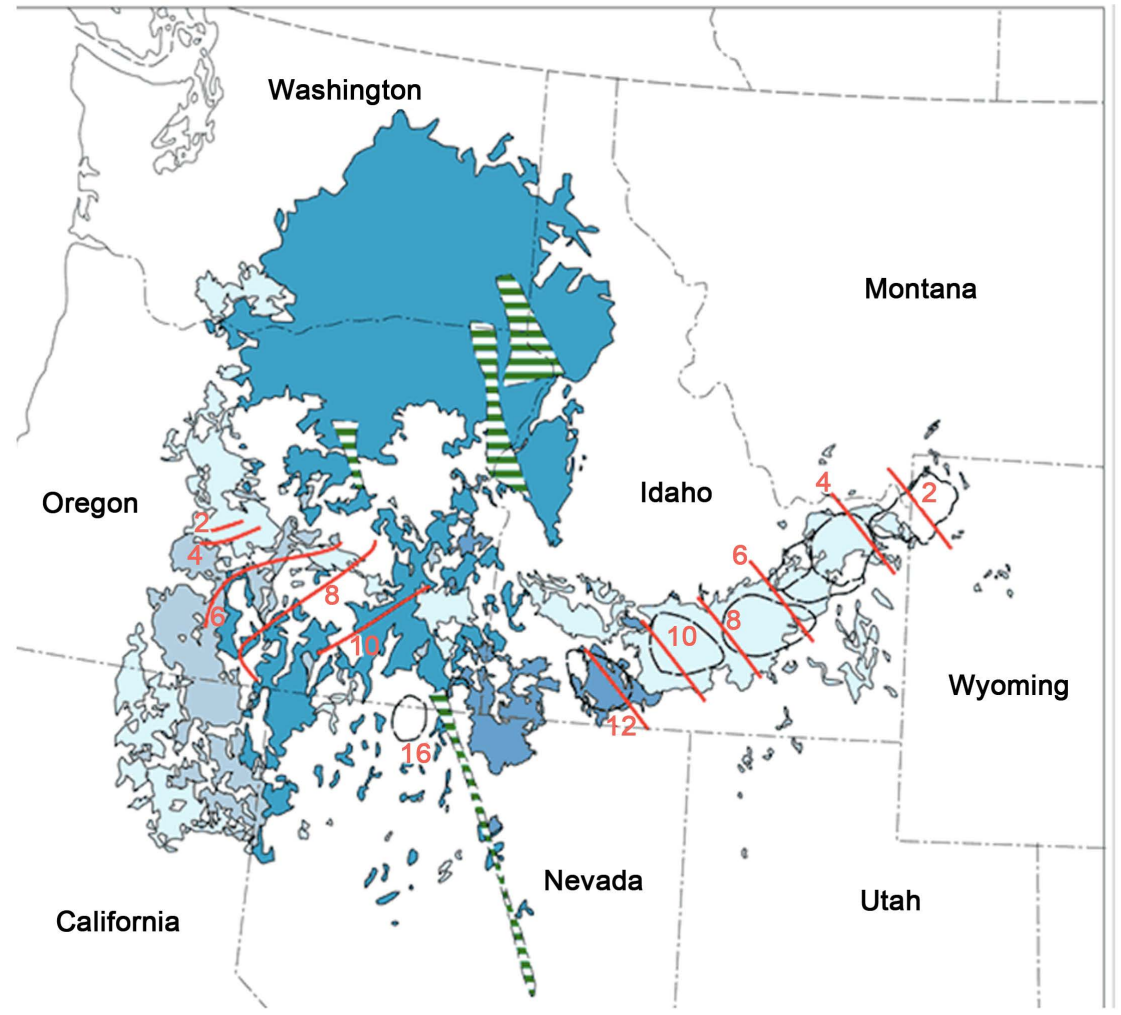

Figure 1. The Yellowstone resurgent calderas forming the hotspot track from NE California to the National Park in NW Wyoming (courtesy of mantleplumes.org). Also shown are various lithological units of the Columbia River Basalt Province. 
Mantle plumes have never been observed by seismic tomography, and would not be likely to be seen even if such existed, because the mantle is essentially transparent to seismic tomography. Not to mention the mathematical difficulties of deconvolution involved, an inherently unstable process, even if all else was favorable.

Using continental as well as oceanic empirical data from the Pacific Ocean and the Gulf of Mexico Nash-Perkins discovered that the Yellowstone "hotspot" thermal anomaly (YS) in the mantle produced more than one hundred forty caldera eruptions, resulting in the creation of a hotspot track from NE California to NW Wyoming, caused by volcanic activity with eruptions piercing the crust above (Nash \& Perkins, 2002, 2012).

As the crustal plate shifts across the anomaly due to plate tectonics this leads to a series of giant volcanic calderas of the resurgent or supervolcano type strung out along a line, called a hotspot track, from NE California through N Nevada and S Idaho to the present location of the National Park in NW Wyoming.

The post-impact calderas are age limited by the earliest one among them, High Rock Caldera just East of the Nevada-California state line, which dates to about $16.4 \mathrm{Ma}$ (Nash \& Perkins, 2002, 2012).

The age of the total magmatic complex including the CRBP extends to $16.6 \mathrm{Ma}$ by dating basaltic \& silicic eruptives. For a detailed geological description and analysis see the article by G. R. Foulger on her mantleplumes.org website.

\section{YS Meteorite Impact Crater Found}

Additionally for this case, we are very fortunate in that a large caldera, located in the Modoc plateau and at least $160 \mathrm{~km}$ in diameter, a compound crater created by cosmic body impact, has been found and now can be reported here. The crater is at the precise location (the Modoc plateau in NE California) where one would expect the very starting point of the YS hotspot track of Mid-Miocene age, by the Nash-Perkins date of 16.6 Ma (Nash \& Perkins, 2002, 2012).

There are two parts of the impact structure that have been identified so far, mere remnants of the original impact crater as the entire region has been subject to extensive geological reworking by at least two orogenies, the Cascades and the Sierra, at this western cratonal margin of the North American continent. The greater part still awaits mapping and detailed geological study.

Reported here for the first time is our discovery of a part characteristic of many impact craters, the central ring wall structure and central uplift, locally known as "Chalk Mountain", located in Shasta County, Northern California. Here, the underlying sedimentary layers of diatoms have surged into a giant central cone of 4,100 ft eminence above a circular moat inside a $40 \mathrm{~km}$ diameter ring wall.

The very size of this central rebound cone speaks to the magnitude of the impact. Map coordinates at the summit are $40.994 \mathrm{~N}, 121.809 \mathrm{~W}^{1}$.

Chalk Mountain rises to an altitude of $5800 \mathrm{ft}$ above sea level at the center of the crater wall. The circular moat forms a canyon in which the Pit River flows winding around 
Chalk Mountain in a wide, almost semicircular bend. The river's turn as it departs from the canyon gives its name to the town of Big Bend, Shasta County (elevation 1,700 ft).

A second, non-central, outlier part of the crater had been discovered earlier, as the initial discovery of the the caldera by Tom Bowens in his 1998 MS thesis at CSM (Bowens \& Gross, 1998) ${ }^{2}$. Bowens \& Gross indicate that they believe the center of the caldera to be located in Stone Coal Valley, $40 \mathrm{~km}$ WSW of the city of Alturas, CA. The map coordinates are $41.364 \mathrm{~N}, 121.019 \mathrm{~W}$. However as stated, the actual center of the impact crater is located approximately a further $80 \mathrm{~km}$ WSW of Stone Coal Valley, at Chalk Mountain.

Tom also has an AGU joint abstract with his advisor that provides additional detail of the caldera (Bowens \& Gross, 2001). The delay of three years after graduation from CSM may be the result of later, post-thesis study, as the remarks in the abstract do not appear to be represented fully in the text of the thesis.

In their abstract, the authors have described the structure in considerable geological detail, reproduced here next:

Regional geologic mapping within the Modoc Plateau has resulted in the discovery of a large volcano-tectonic anomaly some $21-\mathrm{km}$ in diameter approximately $50-\mathrm{km} W \mathrm{WS}$ of the city of Alturas in Modoc County, California. Centrally located within this anomaly lies a structural depression some $11 \mathrm{~km}$ in diameter which, based on structural, lithologic, and geophysical characteristics, is believed to represent a deeply eroded mid-Miocene caldera. The region extending outward some 5-km from the proposed caldera displays a sharp, localized structural deflection from a NNW to a WNW structural grain. Lying inboard of this deflection, a series of regionally discordant $E$ - $W$ to $N E$ trending, generally down to the north, normal faults were discovered which are believed to represent rim faults to an ancient caldera. Bedding within the hanging wall of these discordant structures displays highly contorted and regionally anomalous dips. By stereographic removal of the regional northeast dip overprinting the area, the anomalous dips were found to display a radial, steeply inward dipping pattern in close proximity to the proposed rim structures while dips located further inboard are generally flatlying. Lithologies within the proposed caldera are regionally anomalous and include abundant tuffaceous and flow dominated breccias, closed basin organic sedimentary facies, and an anomalous concentration of volcanic centers of both mafic and felsic compositions. One of these intrusives was age dated at $12.9 \mathrm{Ma}$ indicating the anomaly formed during mid-Miocene time. The location of the proposed caldera is associated with a 20 mgal gravity high, which stands in contrast to a lesser high of $10 \mathrm{mgal}$ associated with the Medicine Lake Caldera some 50-km to the northwest.

Tom Bowens and his advisor appear to have been unaware of Chalk Mountain (Figure 2) as actual center rebound of their caldera. Located in the middle of the volcanic Modoc plateau, Chalk Mountain is an oddity being composed, as the name suggests, of diatomaceous earth which underlies the entire volcanic region in a thickness of up to $100 \mathrm{ft}^{3}$.

${ }^{2}$ Tom now is working as an executive for a mining company active in Siberia.

${ }^{3}$ http://shastacascade.com/accountdetails.php?id=1915 


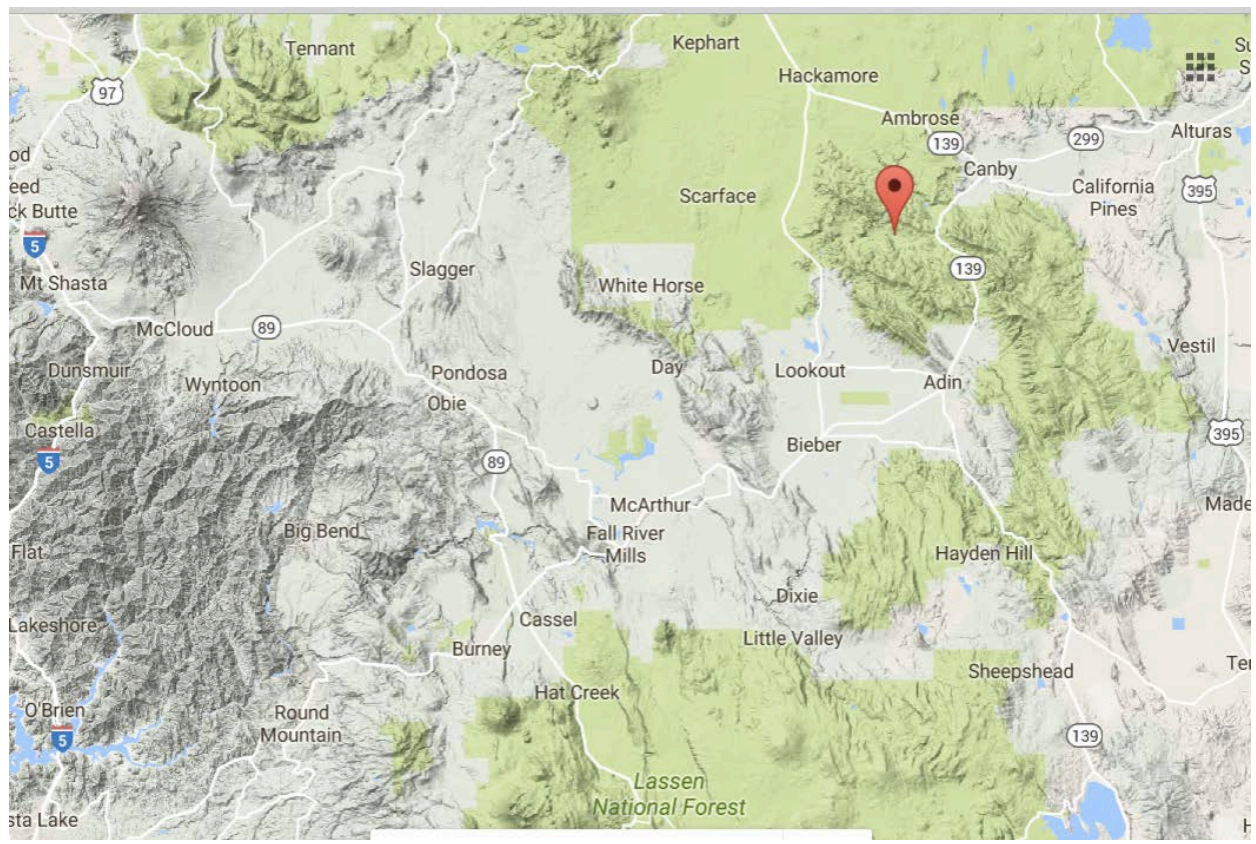

Figure 2. On the lower left, the inner crater ring, at its center Chalk Mountain, SE from the town of Big Bend. To the ENE, remnants of two outer rings. At a distance of $80 \mathrm{~km}$ ENE, Stone Coal Valley is the marked site on the second outer ring, where Tom Bowens found (parts of) a caldera (Google terrain). The geographic region shown measures $150 \times 100 \mathrm{~km}$ approximately.

The combined structure of Stone Coal Valley as described in the Bowens-Gross abstract and of Big Bend-Pit river-Chalk Mountain presumably is the remnant of a much larger multi-ring formation, which in turn suggests a very large impact, that still is partially visible but mostly became obliterated during subsequent Cascadian orogeny (6 $\mathrm{Ma}$ ) in the West and North and an ongoing Sierra Nevada uplift process since Eocene times in the South. The original caldera would have been at least $160 \mathrm{~km}$ in diameter.

As described here, the caldera may be identified as of cosmic object impact origin from its characteristic central rebound uplift made of sedimentary non-volcanic material, and therefore of unquestionable ET impact origin. It can now be identified as the YS impact crater, by its geographic location at the head of the YS hotspot track, as seen from the graphic in the mantleplumes.org website shown above.

Field research in the Modoc Plateau, additional to the detailed cited results of Tom Bowens, will confirm this our first report of a $160 \mathrm{~km}$ Modoc Crater, and establish further criteria through mapping of the exact extent and age of the partially obliterated impact structure in all its details, which will bring out the system of rim faults, remnants of the multi-ring complex impact crater. It would be shown to precede orogenies that have occurred in the region after the mid-Miocene impact event.

\section{Explosive Volcanism and ET Origin of Hotspots and LIPs}

Here we explain a hotspot generation mechanism by cosmic body impact, which indicates how LIPs can be derived from thin crust large impacts-probably comets from 
Centaur \& Kuiper belts or perhaps Oort cloud-thin crust implies a deep oceanic site, with few exceptions, such as the exceptional YS/CRBP impact considered here, which occurred in shelf sediments at or near the cratonal margin.

The YS impact was in fact thin crust, but probably on the outer continental shelf or slope back in the Miocene, and that is why it is chalk, unlike the surrounding igneous rocks. Tom Bowens in an email to me stated that when he did his thesis, he had thought that his Stone Coal Caldera must have to do with Yellowstone.

Our present understanding of explosive volcanism, and of the importance of volatiles, largely is due to Steve Sparks, Bristol University (Gilbert \& Sparks, 1998). Steve Sparks has won several prestigious awards, including the 2015 Vetlesen prize, LDEO, Columbia Univ, considered the "Nobel prize of the Earth Sciences." Sparks has given the explanation for the lower solidus due to dissolved volatiles (Sparks, 2003):

Degassing has profound effects on the phase equilibria of magmas, because rather small amounts of water dissolved in magmas can reduce their liquidus temperature [and hence the solidus] by hundreds of degrees. Conversely, degassing can cause spontaneous crystallization. While these effects have been known about for many decades, it is only relatively recently that their significance for understanding volcanic processes had been widely appreciated. Crystallization due to degassing may prove as important as cooling in igneous petrogenesis.

Based on this, we next are able to suggest a plausible mechanism for the generation of hotspots by thin-crust bolide impact typically applicable to oceanic impacts which are responsible for Large Igneous Provinces (LIP).

The volcanism is explosive \& resurgent because the volatiles come out of solution in the explosion and thereby are depleted locally in the mantle. The cavity almost immediately collapses \& refills, so a new cycle starts: The volatiles by diffusion replenish the magmatic melt from surrounding mantle volumes in the vicinity, and this eventually leads to another explosion.

The time factor for the diffusive replenishment is important and changes as the hotspot evolves, according to the findings of Nash-Perkins (Nash \& Perkins, 2002). In their study of the YS ash layer sequence, marking caldera eruptions, they found initial time intervals of a few ten thousand years, evolving to 600,000 years in the later to recent stage of YS. As time progresses, the hotspot anomaly extends to a greater volume enlarging itself both in depth and width. In the case of the Hawaiian hotspot ${ }^{4}$, there has been a late evolution to a nearly continuous eruption.

\section{Conclusion}

So here, we have a key example in Yellowstone, the most famous hotspot, \& the Columbia River Basalts, perhaps the most famous LIP, at least the first one of which I had ever heard, provably not resulting from a deep mantle plume but from a Miocene impact crater in the Modoc plateau from where the hotspot track goes ENE straight toward NW Wyoming, site of the present-day National Park.

${ }^{4}$ Here believed to be similarly generated by end-Permian impacts in the West-Siberian Basin \& S Kara Sea (unpublished). 
Here reported in this essay, we are demonstrating that this LIP, and hence presumably all LIPs, are caused by cosmic object-bolide meteorite-impacts, on the strength of our discovery of parts of a cosmogenic complex impact crater, the Bowens Stone Coal Valley Caldera and $80 \mathrm{~km}$ to the WSW the true center Chalk Mountain within a $40 \mathrm{~km}$ innermost circular ring wall, at the exact place in NE California, the volcanic Modoc plateau from where the line of YS supervolcano calderas appears to emerge.

Also based on prior geological work cited above, we are able to put to rest two classical geological theories that up until now have been accepted widely, the Morgan theory of mantle plumes and the no-impact-volcanism theory of Ivanov-Melosh.

This example can serve as a perfect test case because the Yellowstone hotspot cannot have arisen from deep mantle convection as demonstrated in the above cited article by Christiansen et al. (2002). Instead, above we have proved the origin by a large bolide meteorite impact in the volcanic Modoc plateau.

The issue of impact volcanism has been a concern for years, geologists being largely gathered behind the Wilson-Morgan idea of mantle plumes rising from the core-mantle boundary, a narrow zone called the D" (Wilson, 1963; Morgan, 1971). These plumes are held responsible for large igneous provinces (LIP).

This one example therefore now invalidates a paper by Ivanov and Melosh that is cited widely by geologists, where they claim to prove that impact volcanism cannot occur (Ivanov \& Melosh, 2003).

Melosh, elected member NAS for his pioneering work on impacts, in his paper with Ivanov (Ivanov \& Melosh, 2003) is basing his analysis on incorrect mantle geo-cosmochemistry, ignoring the fact that the mantle has copious volatiles dissolved lowering the melting temperature, the solidus, so that explosive volcanism can occur once a thin crust impact excavates a deep hole, as deep initially as $10-25 \%$ of the crater diameter, causing an upper mantle thermal anomaly or hotspot to form. Here is a typical quote citing Ivanov-Melosh which is taken from a paper by several geologists with prominent names including Alvarez and Renne (Richards et al. 2015):

Also, a Chicxulub-size impact does not in any case appear capable of generating a large mantle melting event (Ivanov and Melosh, 2003).

Yes, ironically LIPs are based on mantle "plumes", but not upwelling ones from deep D" by convection, but exactly opposite growing downward by mantle depletion after an impact cavity opens up the mantle.

Also, upon painstaking review of relevant publications, it can be noted that the claim of early Deccan volcanism, pre-K/T extinction event, which is routinely cited in the literature, cannot be verified and should be seen as spurious. Quite possibly confusion with Rajmahal lavas may have led to this mistake initially.

Once alerted to this situation, the pervasive effects of ET object impacts are visible everywhere on Earth, from the effects on, and initiation of, plate tectonics, to the realization that craters are a dime a dozen, especially on old surfaces, including ocean bottom, and such antipodal effects as chaotic terrains caused by bolide impacts-in the form of granitic extrusions. A great example is Rio de Janeiro's Sugarloaf Mountain, antipodal of the Ontong Java impact that created the eponymous LIP. 


\section{References}

Anderson, D. L., \& Natland, J. H. (2005). A Brief History of the Plume Hypothesis and Its Competitors: Concept and Controversy. In G. R. Foulger, J. H. Natland, D. C. Presnall, \& D. L. Anderson, Eds., Plates, Plumes, \& Paradigms, GSA Special Paper 388, 119-145.

Bowens, T. E., \& Gross, L. T. (1998). Geology and Mineral Deposit Reconnaissance in the Stone Coal Valley Region, Modoc County, California. Thesis (M.Sc.), Colorado School of Mines.

Bowens, T. E., \& Gross, L. T. (2001). Probable Mid-Miocene Caldera in the Modoc Plateau, Northeast California, Details. AGU Fall Meeting. http://abstractsearch.agu.org/meetings/2001/FM/V52A-1047.html

Christiansen, R. L., Foulger, G. R., \& Evans, J. R. (2002). Upper-Mantle Origin of the Yellowstone Hotspot. Geological Society of America Bulletin, 114, 1245-1256. http://dx.doi.org/10.1130/0016-7606(2002)114<1245:umooty >2.0.co;2

Fouch, M. J. (2012). The Yellowstone Hotspot: Plume or Not? Geology, 40, 479-480. http://dx.doi.org/10.1130/focus052012.1

Foulger, G. R. (2006). Yellowstone. http://www.mantleplumes.org/Yellowstone.html

Gilbert, J. S., \& Sparks, R. S. J. (Eds.) (1998). The Physics of Explosive Volcanic Eruptions. Geologial Society Special Publication 145, London: The Geologial Society.

Ivanov, B. A., \& Melosh, H. J. (2003). Impacts Do Not Initiate Volcanic Eruptions: Eruptions Close to the Crater. Geology, 31, 869-872. http://dx.doi.org/10.1130/G19669.1

Morgan, W. J. (1971). Convection Plumes in the Lower Mantle. Nature, 230, 42-43. http://dx.doi.org/10.1038/230042a0

Richards, M. A., Alvarez, W., Self, S., Karlstrom, L., Renne, P. R., Manga, M., Sprain, C. J., Smit, J., Vanderkluysen, L., \& Gibson, S. A. (2015). Triggering of the Largest Deccan Eruptions by the Chicxulub Impact. Geological Society of America Bulletin, 127, 1507-1520. http://dx.doi.org/10.1130/B31167.1

Sparks, R. S. J. (2003). Dynamics of Magma Degassing. In C. Oppenheimer, D. M. Pyle, \& J. Barclay, Eds., Volcanic Degassing, London: The Geological Society. http://dx.doi.org/10.1144/gsl.sp.2003.213.01.02

Wilson, J. T. (1963). A Possible Origin of the Hawaiian Islands. Canadian Journal of Physics, 41, 863-870. http://dx.doi.org/10.1139/p63-094 
Submit or recommend next manuscript to SCIRP and we will provide best service for you:

Accepting pre-submission inquiries through Email, Facebook, LinkedIn, Twitter, etc. A wide selection of journals (inclusive of 9 subjects, more than 200 journals)

Providing 24-hour high-quality service

User-friendly online submission system

Fair and swift peer-review system

Efficient typesetting and proofreading procedure

Display of the result of downloads and visits, as well as the number of cited articles

Maximum dissemination of your research work

Submit your manuscript at: http://papersubmission.scirp.org/

Or contact ojpp@scirp.org 